\title{
Use of Drains After Evacuation of Chronic Subdural Hematomas
}

\section{Chengyuan $\mathrm{Wu}, \mathrm{MD}$}

Department of Neurological Surgery, Thomas Jefferson University, Philadelphia, PA

A subdural hematoma (SDH) is a collection of blood that accumulates between the surface of the brain and its outermost covering, called the dura. These types of hematmas usually result from tears in bridging veins that cross this subdural space, which is typically the result of some form of trauma. A patient's risk of developing a SDH increases with age as the brain tends to pull away from the dura, therefore stretching the bridging veins and increasing the subdural space. In addition the risk of progression of a SDH is greater if the patient is already regularly taking an anticoagulant such as Aspirin, Plavix, or Coumadin.

\begin{tabular}{|l|l|}
\hline \multicolumn{2}{|l|}{ Subdural Hematomas Can Lead to a Variety of Symptoms ${ }^{3}$ Including: } \\
\hline Headache & Lethargy \\
\hline confusion or disorientation & Weakness \\
\hline Numbness & Difficulty with balance or walking \\
\hline Nausea and/or vomiting & Slurred speech \\
\hline Loss of consciousness & Seizures \\
\hline
\end{tabular}

The treatment of symptomatic SDH involves surgical evacuation, which can be achieved via dburr holes or through a craniotomy. After this initial procedure to evacuate the SDH, some surgeons will place a subdural drain to help ensure that all of the blood products are removed and to reduce the risk of recurrence of the SDH; however, not all surgeons will do so and the use of subdural drains is a matter of debate ${ }^{2}$. Major arguments against drain placement include increased risk of damage to the brain with placement of a subdural drain and an increased risk of infection in leaving a drain in place. These concerns, however, are more or less anecdotal since recent evidence-based studies have demonstrated the efficacy of leaving a subdural drain in place.

\begin{tabular}{|l|l|l|}
\hline Table l: Recurrence & Result with Drain & Result Without Drain \\
\hline Study & $4 \%(6 / 165)$ & $30 \%(130 / 442)$ \\
\hline Ramachandran et al. $^{3}$ & $7.6 \%(17 / 224)$ & N/A \\
\hline Gazzeri et al. $^{1}$ & $9.3 \%(10 / 108)$ & $24 \%(26 / 107)$ \\
\hline Santarius et al. $^{3}$ & $6.6 \%(8 / 121)$ & \\
\hline Yu et al $^{5}$ & N/A & N/A \\
\hline $\begin{array}{l}\text { Rate was } 16.3 \% \text { for patients with }<3 \\
\text { days of drainage (7/43 cases), } 1.3 \% \\
\text { with 3 or more days (1/78 cases). }\end{array}$ & & \\
\hline
\end{tabular}

\section{Table II: MORTALITY}

\begin{tabular}{|l|l|l|}
\hline Study & Result with Drain & Result without Drain \\
\hline Santarius et al. ${ }^{3}$ & $8.6 \%(9 / 105)$ & $18.1 \%(19 / 106)$ \\
\hline Gazzeri et al. $^{1}$ & $0.9 \%(2 / 224)$ & N/A \\
\hline Zumofen et al. $^{5}$ & $3.4 \%(5 / 147)$ & N/A \\
\hline
\end{tabular}

Recent published studies including a single randomized controlled trial have evaluated the effect of placing a subdural drain with all other factors being held equal. The results of a literature search are presented in Table I, which summarizes recurrence rates, and in Table II, which summarizes overall mortality.

The only available randomized controlled study was performed between November 2004 and November 2007 at Addenbrooke's Hospital in Cambridge, UK by Santarius et al. ${ }^{4}$ All patients underwent evacuation with two burr holes and were subsequently randomized to whether a subdural drain was placed. Outcomes were determined with questionnaires obtained at 30 days and at 6 months. A few shortcomings of this study include the inability to mask treatment allocation, missing data from incomplete questionnaires and incomplete recording, and the fact that it was a single-center study. Nevertheless, this study was able to demonstrate that using drains reduced both the recurrence rate of SDH and the 6 months' mortality rate. Furthermore, there was no difference in length of hospital stay or in overall complication rates, including infection rates.

Another study that compared cohorts with and without drains was performed by Ramachandran et al. ${ }^{3}$ They found that recurrence rates were lower when drains were used; but mortality rates were not reported within the drain and no-drain cohorts. As a retrospective study, drawing on data collected in the normal course of operations, it lacks the reliability of prospective studies, which are designed specifically to focus on the effect of an intervention.

In the evidence-based hierarchy, case series within a single cohort are considered to be the least reliable. In three such studies reviewed, all patients received drains and their outcomes were evaluated. $\mathrm{Yu}$ et $\mathrm{al}^{5}$ was a single cohort study involving procedures performed from January 1997 to June 2008. All patients had subdural drains placed, and a subgroup analysis indicated that patients whose drains were in for longer periods (at least three days) had lower recurrence rates. In addition, prolonged duration of drainage did not increase rate of infection; however, mortality was not reported 
in this study. Gazzeri et al. ${ }^{1}$ and Zumofen et al. ${ }^{5}$ reported case series in which extracranial drains were used. Although mortality rates were comparable or lower to cohorts with subdural drains, and overall morbidity was decreased, recurrence rates were generally higher

Taking all of these studies into consideration, the following guidelines for drains in $\mathrm{SDH}$ is proposed:

- Drains should be placed after evacuation of chronic subdural hematomas.

- Drains should remain for 72 hours postoperatively
Placement of a subgaleal drain may be a safer method, but may not be equally as effective as a subdural drain.

\section{REFERENCES}

1. Gazzeri R, Galarza M, Neroni M, Canova A, Refice GM Esposito $\mathrm{S}$. Continuous subgaleal suction drainage for the treatment of chronic subdural haematoma. Acta Neurochir (Wein). 2007;149(5):487-93; discussion 493. Epub 2007 Mar 28.

2. Koivisto T, Jääskeläinen JE. Chronic subdural haematoma--to drain or not to drain? Lancet. 2009 Sep 26;374(9695):1040-1.

3. Ramachandran R, Hegde T. Chronic subdural hematomas-causes of morbidity and mortality. Surgical Neurol. 2007 Apr;67(4):367-72; discussion 372-3.
4. Santarius T, Kirkpatrick PJ, Ganesan D, Chia HL, Jalloh I, Smielewski P, Richards HK, Marcus H, Parker RA, Price SJ, Kirollos RW, Pickard JD, Hutchinson PJ. Use of drains versus no drains after burr-hole evacuation of chronic subdural haematoma: a randomised controlled trial. Lancet. 2009 Sep 26;374(9695):1067-73

5. Yu GJ, Han CZ, Zhang M, Zhuang HT, Jiang YG. Prolonged drainage reduces the recurrence of chronic subdural hematoma. Br J Neurosurg. 2009 Dec;23(6):606-11.

6. Zumofen D, Regli L, Levivier M, Krayenbühl N. Chronic subdural hematomas treated by burr hole trepanation and a subperiostal drainage system. Neurosurgery. 2009 Jun;64(6):1116-21; discussion 1121-2.

\section{Brain power}

\section{Jefferson \\ Hospital for Neuroscience}

1-800-JEFF-NOW
The Jefferson Acute Stroke

Center is Joint Commissioncertified and has among the highest number of stroke

discharges in Pennsylvania. 